\title{
ANALISA PENGENDALIAN KUALITAS PADA HOME INDUSTRI MAKANAN
}

\author{
Sopyan Saori, Laila Hamidah, Nur Azmi, Aldi Rouf Ramdan dan Muhammad \\ Reza \\ Universitas Muhammadiyah Sukabumi, Jawa Barat, Indonesia \\ Email: sopyansaori@ummi.ac.id, lailah050@ummi.ac.id, nurulazmi294@ummi.ac.id, \\ aldirouf123@ummi.ac.id, 11047mohammadreza@ummi.ac.id
}

\section{Abstract}

The purpose of this research is to explain whether quality control in MSMEs Mochi Bakat Jaya is able to provide satisfaction for consumers and can be superior to competitors and identify the factors that cause damage to the uk prodUMKM Mochi Bakat Jaya. This research method uses primary data which is then analyzed based on check sheet and made pareto diagram and causal diagram. The results showed that the failed product in MSMEs Mochi Bakat Jaya is the income of inappropriate peanuts by $53 \%$ and the dough is too hard by $43 \%$. Fthe lead actor who causes damage or incompatibilityto theproduct is human and method. The number of mochi products produced by MSMEs Mochi Bakat Jaya during November 2020 amounted to 2,391 and the total number of failed or defective products was 150. By analyzing using pareto diagrams, the main factor that most affects the damage or incompatibility of mochi products is the incompatibility of $53 \%$ of the total number of failed or defective products. Followed by a dough too hard by $43 \%$. Furthermore, by using a causal diagram it can be concluded that the main factors that cause damage or incompatibility in mochi products are human and method.

Keywords: quality control; pareto diagrams; casual diagrams

\section{Abstrak}

Tujuan dari penelitian ini adalah untuk menjelaskan apakah pengendalian kualitas pada UMKM Mochi Bakat Jaya mampu memberikan kepuasan bagi para konsumen serta dapat lebih unggul dari pesaing dan mengidentifikasi faktor-faktor yang menyebabkan kerusakan pada produk UMKM Mochi Bakat Jaya. Metode penelitian ini menggunakan data primer yang selanjutnya dianalisa berdasarkan lembar check sheet serta dibuat diagram pareto dan diagram sebab-akibat. Hasil penelitian menunjukkan bahwa produk gagal pada UMKM Mochi Bakat Jaya adalah pemasukan kacang tidak sesuai sebesar 53\% dan adonan terlalu keras sebesar $43 \%$. Faktor utama yang meyebabkan kerusakan atau ketidaksesuaian pada produk tersebut adalah manusia dan metode. Jumlah produk mochi yang dihasilkan oleh UMKM Mochi Bakat Jaya selama bulan November 2020 sebanyak 2.391 dan total keseluruhan produk gagal atau cacat sebanyak 150. Dengan menganalisis menggunakan diagram pareto, faktor utama yang paling mempengaruhi kerusaakan atau ketidaksesuaian pada produk mochi adalah pemasukan kacang tidak sesuai sebesar 53\% dari jumlah produk gagal atau cacat secara menyeluruh. Dilanjut dengan adonan terlalu keras sebesar $43 \%$. Selanjutnya dengan menggunakan 
diagram sebab-akibat dapat disimpulkan bahwa faktor utama yang meyebabkan kerusakan atau ketidaksesuaian pada produk mochi adalah manusia dan metode.

Kata kunci: pengendalian kualitas; diagram pareto; diagram sebab-akibat

\section{Pendahuluan}

Kualitas merupakan suatu hal yang paling diperhatikan bagi perusahaan agar bisa mencapai tujuannya. Untuk mencapai kualitas yang baik perlu strategi secara menyeluruh agar bisa berkompetisi dengan para pelaku usaha lain. Kualitas yang baik akan dihasilkan dari proses yang baik dan sesuai standar kualitas yang telah ditentukan berdasarkan kebutuhan pasar. Situasi aktual menunjukkan bahwa perusahaan yang sukses dan layak harus mengembangkan rencana yang berkualitas. Karena melalui prosedur berkualitas tinggi akan mampu secara efektif menghilangkan pemborosan dan meningkatkan daya saing perusahaan (Sari \& Purnawati, 2018). Pengendalian kualitas atau Quality Control merupakan aktivitas yang sering dilakukan oleh setiap perusahaan. Tentunya pada saat melakukan Quality Control yang baik diperlukan biaya tambahan yaitu pengawasan kualitas dan keadaan dimana kerusakan produk yang dihasilkan sangat rendah atau produk rusak ringan (Fakhri \& Kamal, 2010).

Naik turunnya persentase kinerja dapat diakibatkan banyak hal, terutama penurunan kualitas dan kuantitas hasil pekerjaan dari standar kerja yang ditentukan. Banyak faktor yang andil di dalamnya. Perubahan lamanya waktu penyelesaian pekerjaan, kualitas dan kuantitas pekerjaan dihasilkan dapat diakibatkan karena minimnya komunikasi interpersonal antara pimpinan dengan bawahan maupun antar karyawan, sehingga informasi mengenai waktu penyelesaian pekerjaan, kualitas dan kuanntitas hasil pekerjaan masih kurang jelas serta kurang bisa terkejar (Falah, 2020).

Seharusnya Apabila perusahaan tidak memerhatikan pengendalian mutu, perusahaan mungkin tidak perlu memerhatikan pengawasan kualitas. Akan tetapi, perusahaan akan kesulitan dalam memasarkan produknya karena tertinggal dengan perusahaan yang kualitas produknya lebih baik serta jumlah produk yang rusak akan semakin banyak. Pengendalian mutu diperlukan untuk mengarahkan agar kesalahan dalam segi kualitas produk dapat di minimalisir.

Kontribusi Usaha Mikro, Kecil dan Menengah (UMKM) di Indonesia tidak perlu diragukan lagi. Berdasar informasi dari Kementerian Bagian Data - Biro Perencanaan Kementrian Negara Koperasi dan UKM Republik Indonesia, UMKM memberikan berbagai jenis kontribusi, diantaranya adalah kontribusi UMKM terhadap penciptaan investasi nasional, Kontribusi UMKM tehadap Produk Domestik Bruto (PDB) Nasional, kontribusi UMKM dalam penyerapan tenaga kerja nasional, dan kontribusi UMKM terhadap penciptaan devisa nasional (Humaira \& Sagoro, 2018).

UMKM Mochi Bakat Jaya merupakan UMKM yang bergerak dibidang makanan dan juga merupakan home industri yang cukup dikenal oleh pribumi. UMKM Mochi Bakat Jaya sangat memperhatikan kualitas terutama pada kualitas produknya. Akan tetapi dalam proses produksinya ada saja beberapa produk yang terjadi kesalahan atau bisa dibilang produk cacat dalam proses produksi. Oleh karena itu perlu adanya pengendalian mutu dengan metode Diagram Pareto dan Diagram Sebab-Akibat untuk 
mengetahui seberapa banyak produk cacat, apakah masih dalam batas wajar atau bahkan sebaliknya.

Menurut Montgomery dalam (Rani \& Setiawan, 2017) Pengendalian Kualitas adalah suatu kegiatan rekayasa dan manajemen yang melaluinya kita dapat mengukur karakteristik mutu produk, membandingkannya dengan spesifikasi atau persyaratan, dan mengambil ukuran kesehatan yang tepat bila terdapat perbedaan antara tampilan sebenarnya dan tampilan standar.

Dalam proses menciptakan produk yang berkualitas sesuai standar dan selera konsumen sering terjadi penyimpangan-penyimpangan yang tidak diinginkan perusahaan sehingga mengakibatkan kerusakan produk yang tentunya akan menimbulkan kerusakan besar pada perusahaan (Ratnadi \& Suprianto, 2020).

Diagram Pareto berperan penting dalam proses peningkatan kualitas. Diagram Pareto ini adalah gambar yang mengurutkan kejelasan data dari kiri ke kanan dalam urutan pengurutan tertinggi hingga terendah (Bon \& Mustafa, 2013).

Menurut (Nasution, 2010) Diagram Sebab-Akibat adalah suatu Metode terstruktur yang memungkinkan analisis yang lebih detail untuk menemukan penyebab masalah, ketidaksesuaian, dan celah.

Berdasarkan uraian diatas maka tujuan yang akan dicapai pada penelitian ini adalah mengetahui bagaimana UMKM Mochi Bakat Jaya dalam mengendalikan kualitas untuk meminimumkan produk gagal dengan menggunakan metode diagram pareto dan diagram sebab-akibat.

Definisi kualitas memiliki cakupan yang sangat luas, sehingga terdapat berbagai definisi dari kualitas. Kualitas dalam produk menurut (Winarko, 2018), adalah kondisi fisik, fungsi, dan sifat produk terkait yang memenuhi selera dan kebutuhan konsumen berdasarkan nilai uang yang dikeluarkan. Pengendalian kualitas dilakukan secara berurutan dapat menghasilkan produk dalam bentuk komoditas atau layanan yang memenuhi standar yang dipersyaratkan dan terencana, serta meningkatkan kualitas produk yang belum sesuai berdasarkan standar yang telah ditetapkan (Ratnadi \& Suprianto, 2020).

Pengendalian mutu atau pengendalian kualitas memiliki beberapa faktor. Menurut Douglas C. Montgomery dalam (Bakhtiar et al., 2013) faktor-faktor yang mempengaruhi pengendalian kualitas yang dilakukan oleh perusahaan antara lain:

1. Kemampuan pemrosesan. Batasan yang harus dicapai harus disesuaikan dengan kemampuan proses yang ada. Tidak masuk akal untuk mengontrol proses di luar kemampuan proses yang ada.

2. Spesifikasi yang berlaku. Dari perspektif kapabilitas proses dan realisasi kebutuhan konsumen dari produk-produk ini, spesifikasi hasil produksi yang ingin dicapai harus dapat diterapkan. Dalam hal ini, pertama-tama kita harus menentukan apakah spesifikasi dapat diterapkan dari dua aspek di atas, dan kemudian kita dapat memulai pengendalian kualitas dalam prosesnya.

3. Tingkat kegagalan yang dapat diterima. Tujuan dari proses pengendalian adalah untuk mengurangi produk yang ada di bawah standar. Tingkat pengendalian yang diberlakukan tergantung pada kuantitas dan biaya kualitas produk di bawah standar 
yang dapat diterima. Biaya mutu sangat mempengaruhi tingkat pengendalian mutu produk yang dihasilkan, dan biaya mutu berkorelasi positif dengan produksi produk bermutu tinggi.

Tujuan dari pengendalian kualitas adalah untuk meningkatkan kepuasan konsumen dan dalam proses produksi dapat diproduksi dengan biaya yang murah, serta proses dapat diselesaikan sesuai dengan waktu yang telah ditentukan (Fakhri \& Kamal, 2010).

Untuk mengontrol kualitas produk, perusahaan dapat menggunakan metode diagram pareto dan diagram sebab-akibat. Diagram Pareto adalah gambar yang mengurutkan klasifikasi data dari kiri ke kanan dalam urutan pengurutan tertinggi hingga terendah (Bon \& Mustafa, 2013). Hal ini dapat membantu menemukan masalah terpenting yang perlu segera diselesaikan (peringkat tertinggi), daripada masalah yang tidak perlu segera diselesaikan (peringkat terendah) (Ariani dalam Ramadhani et al., 2014). Penggunaan diagram pareto dapat dilakukan dengan menggunakan lembar periksa atau check sheet. Lembar periksa (check sheet) adalah alat untuk memudahkan proses pengumpulan data (Sutrisno \& Huang, 2013). Yang dimana data tersebut dapat membantu dalam menggunakan metode diagram pareto.

Diagram sebab-akibat bisa juga disebut sebagai diagram tulang ikan (Fishbone Chart). Heizer dan Render dalam (Elmas, 2017), menyatakan bahwa diagram ini disebut juga diagram tulang ikan (Fishbone Chart) dan bermanfaat untuk menunjukkan faktor-faktor utama yang mempengaruhi kualitas dan permasalahan yang kita teliti. Selain itu, kita juga dapat melihat lebih detail faktor-faktor yang mempengaruhi dan mempengaruhi faktor-faktor utama tersebut, seperti bentuk tulang ikan pada Fishbone Chart yang ditunjukkan oleh panah. Prinsip yang digunakan untuk membuat diagram sebab akibat ini adalah sumbang saran atau brainstorming. Faktor penyebab dalam diagram sebab-akibat adalah: Man (manusia), Material (bahan baku), Machine (peralatan/mesin), Method (proses), Measurement (pengukuran), dan Environment (lingkungan). (Darsono, 2013).

Tujuan penelitian ini adalah untuk mengetahui apakah pengendalian kualitas berimplikasi baik bagi UMKM Mochi Bakat Jaya serta untuk mengetahui apakah jumlah produk gagal masih dalam batas wajar atau tidak. Penelitian yang dilakukan oleh (Elmas, 2017) dengan judul "Pengendalian Kualitas Dengan Menggunakan Metode Statistical Quality Control (SQC) Untuk Meminimumkan Produk Gagal Pada Toko Roti Barokah Bakery", bahwa setelah melakukan analisis diagram sebab akibat, dapat diketahui faktor utama penyebab terjadinya kegagalan produk dikarenakan kelalaian manusia atau faktor sumber daya manusia. Maka demikian peneliti tertarik untuk melakukan penelitian pada UMKM Mochi Bakat Jaya Kota Sukabumi dengan menggunakan metode diagram pareto dan diagram sebab akibat.

\section{Metode Penelitian}

1. Jenis Penelitian

Penelitian ini dilakukan pada UMKM yang bergerak dibidang makanan ringan yaitu UMKM "Mochi Bakat Jaya” yang terletak di Jl. Kaswari No.24, Selabatu, Kec. 
Cikole, Kota Sukabumi, Jawa Barat. Lokasi penelitian dipilih secara terencana dengan menggunakan data perusahaan pada bulan November 2020.

Jenis dari penelitian yang digunakan adalah deskriptif kuantitatif. Menurut (Sugiyono, 2010), metode kuantitatif dapat diartikan sebagai metode penelitian yang berlandaskan pada filsafat positif, digunakan untuk meneliti pada populasi atau sampel tertentu, pengumpulan data menggunakan instrument penelitian, analisis data bersifat kuantitatif/statistik, dengan tujuan untuk menguji hipotesis yang telah ditetapkan.

2. Populasi dan Sampel

Populasi pada penelitian ini adalah UMKM Mochi Bakat Jaya Kota Sukabumi dengan sampel penelitian adalah pemilik usaha atau manajer UMKM Mochi Bakat Jaya Kota Sukabumi.

3. Sumber Data

Sumber data yang digunakan dalam penelitian ini adalah data primer. Dimana data tersebut dikumpulkan dan diolah sendiri oleh peneliti secara langsung ke UMKM Mochi Bakat Jaya.

4. Metode Analisis Data

Setelah diperoleh data-data dari hasil pengamatan yang dilaksanakan selama satu bulan pada bulan November 2020, maka langkah penelitian selanjutnya adalah menentukan prioritas pemecahan masalah untuk jenis cacat dengan jalan memilih tingkat kecacatan yang ada.

Tahap pertama, penyusunan diagram pareto. Langkah dalam menyusun diagram pareto meliputi:

1. Menentukan masalah apa yang akan diteliti, mengindentifikasi kategori kategori atau penyebab-penyebab dari masalah yang akan diperbandingkan. Setelah itu, merencanakan dan melaksanakan pengumpulan data.

2. Membuat suatu ringkasan daftar yang mencatat frekuensi kejadian dari masalah yang telah diteliti dengan menggunakan formulir pengumpulan data atau lembar periksa.

3. Membuat daftar masalah secara berurut berdasarkan frekuensi kejadian dari yang tertinggi samapi terendah, serta menhitung frekuensi komulatif, persentase dari total kejadian dan persentase dari total kejadian secara komulatif.

4. Menggambar dua buah garis yaitu garis vertikal dan garis horizontal.

Tahap kedua, penyusunan diagram sebab-akibat. Langkah-langkah yang harus dilaksanakan dalam penyusunan digram sebab-akibat atau sering disebut diagram tulang ikan adalah sebagai berikut:

1) Menetapkan karakteristik mutu yang akan dianalisis (dalam hal ini adalah masalah-masalah utama yang penting dan mendesak untuk diselasaikan).

2) Menulis pernyataan masalah itu pada kepala ikan yang merupakan akibat. Tuliskan pada sisi sebelah kanan kepala ikan kemudian gambarkan tulang belakang dari sisi kiri ke kanan dan tempatkan pernyataan masalah itu dalam kotak. 
3) Menulis faktor-faktor penyebab utama yang mempengaruhi masalah kualitas sebagai tulang besar, juga ditempatkan dalam kotak. Faktor-faktor manusia, mesin, peralatan, metode, tenaga kerja, lingkungan, dan lain-lain.

4) Menuliskan penyebab-penyebab yang mempengaruhi penyebab utama, yang dinyatakan sebagai tulang-tulang berukuran sedang.

\section{Hasil dan Pembahasan}

Berdasarkan pada metode penelitian, langkah pertama yang dilakukan untuk menganalisis pengendalian kualitas secara statistik adalah membuat tabel lembar periksa (check sheet), dan berlanjut dengan membuat diagram sebab-akibat berdasarkan pada hasil wawancara.

Jika data-data yang dibutuhkan sudah terkumpul, maka selanjutnya adalah menganalisa data tersebut untuk memecahkan permasalahan yang sedang diteliti (memberikan solusi).

1. Lembar Check Sheet Mochi

Tabel 1

Hasil Pengumpulan Data Novermber 2020

\begin{tabular}{|c|c|c|c|c|c|}
\hline \multirow[b]{3}{*}{ Bulan } & \multirow[b]{3}{*}{$\begin{array}{c}\text { Jumlah } \\
\text { Produksi }\end{array}$} & \multicolumn{2}{|c|}{ Lembar Check Sheet } & \multirow[b]{3}{*}{$\begin{array}{c}\text { Jumlah } \\
\text { Kerusakan }\end{array}$} & \multirow[b]{3}{*}{$\begin{array}{l}\text { Jumlah } \\
\text { Persentase } \\
\text { Rusak (\%) }\end{array}$} \\
\hline & & \multicolumn{2}{|c|}{ Jenis Kerusakan } & & \\
\hline & & $\begin{array}{c}\text { Adonan } \\
\text { terlalu keras }\end{array}$ & $\begin{array}{l}\text { Pemasukan } \\
\text { kacang } \\
\text { tidak sesuai }\end{array}$ & & \\
\hline Minggu ke-1 & 569 & 19 & 22 & 41 & $7,2 \%$ \\
\hline Minggu ke-2 & 638 & 14 & 15 & 29 & $4,5 \%$ \\
\hline Minggu ke-3 & 601 & 17 & 20 & 37 & $6,1 \%$ \\
\hline Minggu ke-4 & 583 & 21 & 22 & 43 & $7,3 \%$ \\
\hline Jumlah & 2.391 & 71 & 79 & 150 & $25,1 \%$ \\
\hline Rata-rata & 597,75 & & & 37,5 & $6,27 \%$ \\
\hline
\end{tabular}

Sumber Data: Data diolah, 2020

2. Diagram Pareto Pada Produk Mochi

Tabel 2

Data Diagram Pareto Ketidaksesuaian Produk Mochi

\begin{tabular}{cccccc}
\hline No & Jenis Cacat & Frekuensi & $\begin{array}{c}\text { Frekuensi } \\
\text { Komulatif } \\
(\boldsymbol{\%})\end{array}$ & Persentase & $\begin{array}{c}\text { Persentase } \\
\text { Komulatif } \\
(\%)\end{array}$ \\
\hline 1. & $\begin{array}{c}\text { Pemasukan kacang } \\
\text { tidak sesuai }\end{array}$ & 79 & 79 & $53 \%$ & $53 \%$ \\
\hline 2. & $\begin{array}{c}\text { Adonan terlalu } \\
\text { keras }\end{array}$ & 71 & 150 & $47 \%$ & $100 \%$ \\
\hline & Jumlah & 150 & & $100 \%$ & \\
\hline
\end{tabular}

Sumber Data: Data diolah, 2020 
Selanjutnya ialah dibuat suatu diagram pareto dari tabel 2 sebagai berikut:

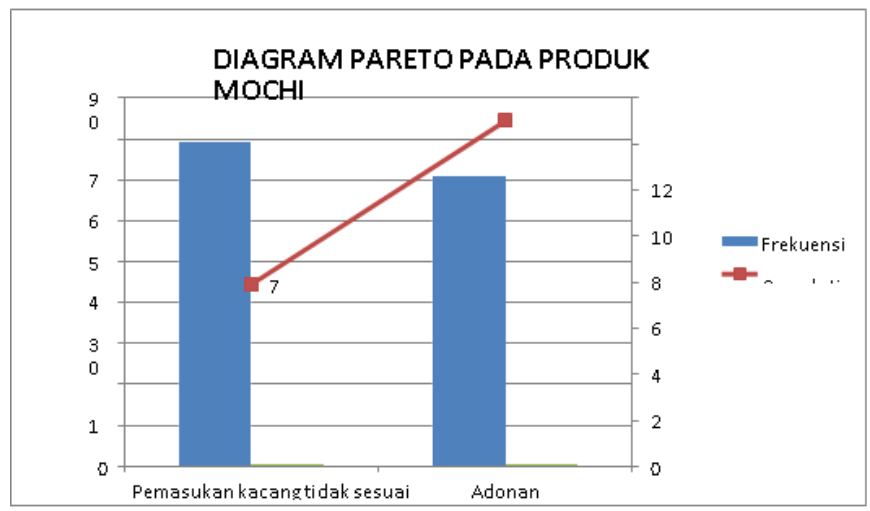

\section{Gambar 1}

Diagram Pareto Produk Tidak Sesuai Pada Produk Mochi

3. Diagram Sebab-Akibat (Fishbone-Diagram)

Dari analisa diagram pareto diketahui bahwa berdasarkan pengamatan yang dilakukan cacat dominan yang terjadi pada produk mochi adalah pemasukan kacang tidak sesuai, dan adonan terlalu keras. Adapun yang dimaksud dengan jenis cacat atau tidak sesuai diatas adalah:

1) Adonan terlalu keras adalah tekstur yang terjadi pada proses produksi mochi yang disebabkan oleh gula yang terlalu ketuaan.

2) Pemasukan kacang tidak sesuai adalah proses dimana tidak seimbangnya antara adonan dan kacang dan dapat mempengaruhi ukurannya yang disebabkan oleh pekerja.

Hubungan antara faktor penyebab dengan masalah yang terjadi yaitu cacat yang dominan akan ditunjukan pada diagram sebab-akibat dibawah ini : 
4. Pemasukan kacang tidak sesuai (53\%)

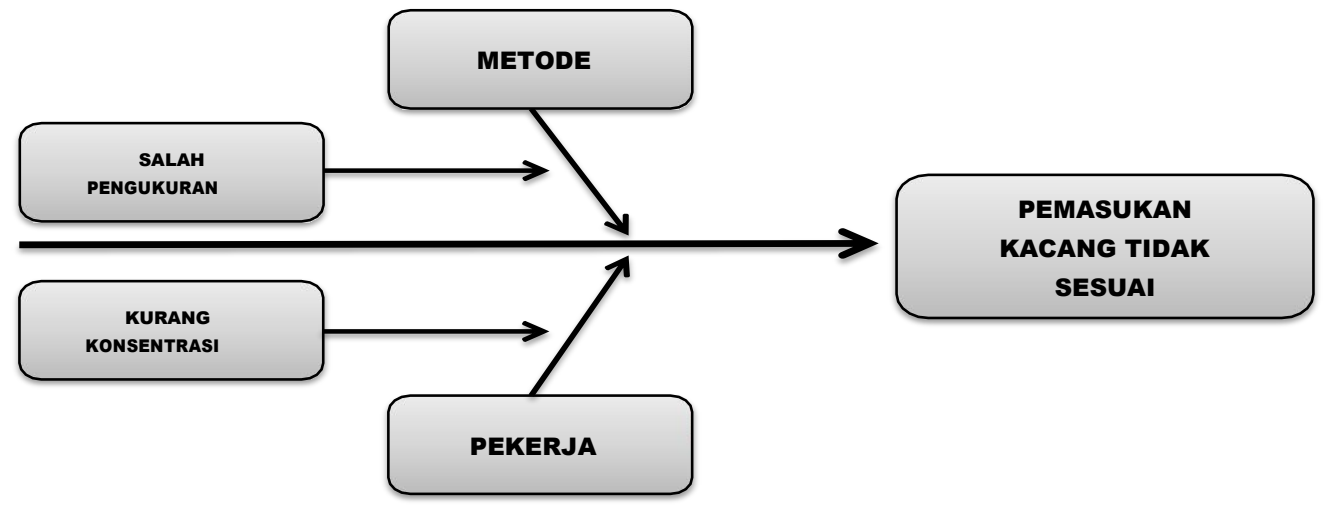

Gambar 2

Diagram Sebab-Akibat Pemasukan Kacang Tidak Sesuai

Dari gambar diatas dapat diketahui adonan terlalu keras disebabkan oleh halhal berikut:

1) Metode : Salah pengukuran, karena saat pengambilan kacang tidak seimbang dengan adonan.

2) Pekerja : Kurang konsentrasi, karena faktor kelelahan para pekerja.

5. Adonan terlalu keras $(47 \%)$

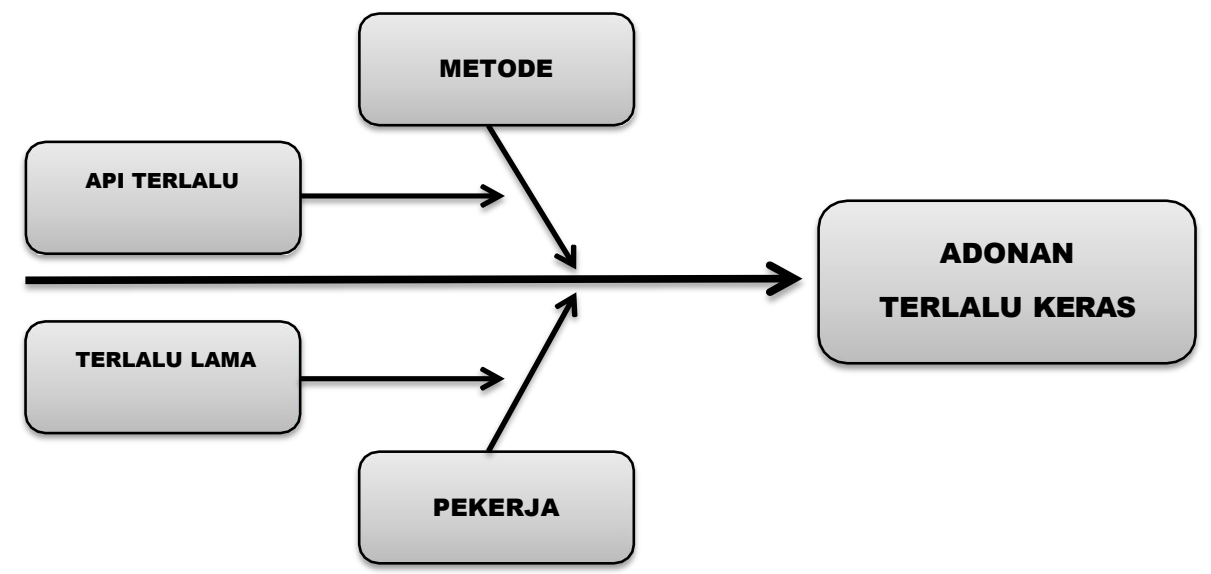

Gambar 3

Diagram Sebab-Akibat Adonan Terlalu Keras

Dari gambar diatas dapat diketahui adonan terlalu keras disebabkan oleh hal-hal berikut:

1) Metode : Api terlalu besar, karena kurangnya memperhatikan waktu proses produksi.

2) Pekerja : Terlalu lama merebus gula, karena faktor kelalaian pekerja. 


\section{Kesimpulan}

Jumlah produk mochi yang dihasilkan oleh UMKM Mochi Bakat Jaya selama bulan November 2020 sebanyak 2.391 dan total keseluruhan produk gagal atau cacat sebanyak 150. Dengan menganalisis menggunakan diagram pareto, faktor utama yang paling mempengaruhi kerusaakan atau ketidaksesuaian pada produk mochi adalah pemasukan kacang tidak sesuai sebesar 53\% dari jumlah produk gagal atau cacat secara menyeluruh. Dilanjut dengan adonan terlalu keras sebesar $43 \%$. Selanjutnya dengan menggunakan diagram sebab-akibat dapat disimpulkan bahwa faktor utama yang meyebabkan kerusakan atau ketidaksesuaian pada produk mochi adalah manusia dan metode.

Adapun saran yang dikemukakan adalah untuk di masa yang akan datang sebaiknya UMKM Mochi Bakat Jaya mengadakan pelatihan bagi para pekerja serta memberikan evaluasi bagi para pekerja atas hasil pekerjaannya. Dengan meminimalisir produk yang gagal atau tidak sesuai, UMKM Mochi Bakat Jaya bisa menggunakan diagram pareto dan juga diagram sebab akibat untuk mengetahui faktor-faktor yang menyebabkan produk gagal atau tidak sesuai dan apabila produk yang tidak sesuai tetapi masih dalam batas wajar dalam artian masih bisa dikonsumsi, lebih baik produk tersebut dijadikan tester bagi konsumen yang membeli ke outlet secara langsung.

\section{BIBLIOGRAFI}

Bakhtiar, S., Tahir, S., \& Hasni, R. A. (2013). Analisa Pengendalian Kualitas Dengan Menggunakan Metode Statistical Quality Control (SQC). Malikussaleh Industrial Engineering Journal, 2(1), 29-36.

Bon, A. T., \& Mustafa, E. M. A. (2013). Impact of total quality management on innovation in service organizations: Literature review and new conceptual framework. Procedia Engineering, 53, 516-529.

Darsono. (2013). Analisis Pengendalian Kualitas Produksi Dalam Upaya Mengendalikan Tingkat Kerusakan Produk. Jurnal Ekonomi - Manajemen Akuntansi, 7(35), 1-17.

Elmas, M. S. H. (2017). Pengendalian Kualitas Dengan Menggunakan Metode Statistical Quality Control (SQC) Untuk Meminimumkan Produk Gagal Pada Toko Roti Barokah Bakery. Jurnal Penelitian Ilmu Ekonomi WIGA, 7, 15-22.

Fakhri, F., \& KAMAL, M. (2010). Analisis Pengendalian Kualitas Produksi di PT. Masscom Graphy dalam Upaya Mengendalikan Tingkat Kerusakan Produk Menggunakan Alat Bantu Statistik. Universitas Diponegoro.

Falah, Z. (2020). Pengaruh Komunikasi Interpersonal dan Lingkungan Kerja terhadap Kinerja Karyawan CV. Syntax Corporation Indonesia. Equivalent: Jurnal Ilmiah Sosial Teknologi, 2(1), 29-39.

Humaira, I., \& Sagoro, E. M. (2018). Pengaruh pengetahuan keuangan, sikap keuangan, dan kepribadian terhadap perilaku manajemen keuangan pada pelaku UMKM 
Sopyan Saori, Laila Hamidah, Nur Azmi, Aldi Rouf Ramdan dan Muhammad Reza

sentra kerajinan batik Kabupaten Bantul. Nominal: Barometer Riset Akuntansi Dan Manajemen, 7(1), 96-110.

Nasution, M. N. (2010). Manajemen Mutu Terpadu, Edisi Ketiga. Ghalia Indonesia. Jakarta.

Ramadhani, G. S., Yuciana, \& Suparti. (2014). Analisis Pengendalian Kualitas Menggunakan Diagram Kendali Demerit (Studi Kasus Produksi Air Minum Dalam Kemasan 240 Ml Di Pt Tiw). Jurnal Gaussian, 3(3), 401-410.

Rani, A. M., \& Setiawan, W. (2017). Menganalisis Defect Sanding Mark Unit Pick Up Tmc Dengan Metode Seven Tools Pt. Adm. JISI: Jurnal Integrasi Sistem Industri, $3(1), 15-22$.

Ratnadi, R., \& Suprianto, E. (2020). Pengendalian Kualitas Produksi Menggunakan Alat Bantu Statistik (Seven Tools) Dalam Upaya Menekan Tingkat Kerusakan Produk. Jurnal Industri Elektro Dan Penerbangan, 6(2).

Sari, N. K. R., \& Purnawati, N. K. (2018). Analisis Pengendalian Kualitas Proses Produksi Pie Susu Pada Perusahaan Pie Susu Di Kota Denpasar. INOBIS: Jurnal Inovasi Bisnis Dan Manajemen Indonesia, 1(3), 290-304.

Sugiyono, S. (2010). Metode penelitian kuantitatif dan kualitatif dan R\&D. Alfabeta Bandung.

Sutrisno, A., \& Huang, Y. (2013). Solid-state NMR: a powerful tool for characterization of metal-organic frameworks. Solid State Nuclear Magnetic Resonance, 49, 1-11.

Winarko, S. (2018). Analisis Pengendalian Kualitas Pada Produk Tahu Putih (Studi Kasus Pada Home Industry Tahu Di Desa Klagen Tropodo Kec. Krian). Universitas 17 Agustus 1945 Surabaya. 